\title{
Mid Frequency Bottom-Interacting Sound Propagation and Reverberation in the Baltic
}

\author{
Jörgen Pihl $^{*}, 1$, Leif Abrahamsson ${ }^{1}$, Sven Ivansson ${ }^{1}$ and Joakim Schön ${ }^{1}$ \\ ${ }^{I}$ FOI, Swedish Defence Research Agency, Department of Underwater Research, Stockholm, Sweden
}

\begin{abstract}
The experiment BAROC (Baltic Acoustics on Rocky Outcrops) was performed in May 2002. Analysis and modelling of part of the received data are reported here, concerning transmission loss and reverberation in a shallow-water area south of Stockholm. LFM pulses were transmitted in two directions with frequency content between 500 and 5500 Hz. In both directions a clear sound channel was observed, for which the optimum propagation frequency was about 4 $\mathrm{kHz}$. Strong bottom reverberation was measured. A ray-trace model has been used as forward model for inversion of bottom parameters with a genetic algorithm. The inversion results were subsequently verified with a parabolic-equation model, and they were used to assess the level of reverberation.
\end{abstract}

Keywords: Low frequency active sonar, shallow water, transmission loss, reverberation, inversion, ray modelling, parabolic equation modelling.

\section{INTRODUCTION}

The experiment BAROC (Baltic Acoustics on Rocky Outcrops) was carried out in May 2002 jointly by the German and Swedish research institutes FWG and FOI. The main purpose was to assess transmission loss and reverberation as a function of frequency and signal bandwidth. Our paper deals with analysis of such data from one of the measurement sites, an area some $90 \mathrm{~km}$ south of Stockholm. Various LFM (linear frequency modulation) pulses, with frequencies between 500 and $5500 \mathrm{~Hz}$, were transmitted to propagation distances up to $30 \mathrm{~km}$. Crucial ingredients in the analysis have been modelling with the ray-trace model MOCASSIN [1] and inversion for bottom parameters with a genetic algorithm. Acoustic measurements from the Baltic are not very common, but some previous examples have been published, e.g. [2-4].

Bottom depths in the area typically vary between 50 and $170 \mathrm{~m}$, with strong range dependence. The salinity (about 7 psu) and the pressure gradient cause an increase of the sound speed in the water from about $1427 \mathrm{~m} / \mathrm{s}$ at a depth of $70 \mathrm{~m}$ to about $1440 \mathrm{~m} / \mathrm{s}$ at a depth of $100 \mathrm{~m}$. Below $100 \mathrm{~m}$, the sound speed increases further, but at a slower rate. At the time of the experiment, the sound speed increased towards the surface, and a sound channel was formed.

After giving an overview of the relevant parts of the experiment in Section 2, normal mode simulations are used in Section 3 to clarify some wave propagation features in a shallow-water waveguide of the pertinent type. It is found that the received pressure levels outside the sound channel carry distinctive information about the bottom type.

*Address correspondence to this author at the FOI, Swedish Defence Research Agency, SE-164 90 Stockholm Sweden; Tel: +46 85550 3594; Fax: +48 85550 3869; E-mail: jorgen.pihl@foi.se
Optimum frequencies of propagation have been investigated previously for downward refracting profiles [5], but they are shifted higher up in the present case.

Data processing issues are discussed in Section 4. Time integration of matched filtered LFM pulse responses has been the preferred method for estimating transmission loss, with careful consideration of multipath arrivals and noise subtraction. Section 5 deals with our modelling tools, an amended version of the MOCASSIN model and a genetic algorithm.

The obtained measurement and modelling results are presented in Section 6. Our conclusions are formulated in Section 7, along with some implications for sonar performance in the Baltic.

\section{EXPERIMENTAL OVERVIEW}

The test site is situated in the vicinity of the Landsort trench. The area has an irregular topography of alternating peaks of crystalline outcrops with sediment deposits in between. A bottom section typical for the site is shown in Fig. (1). The water depth is ranging from less than $10 \mathrm{~m}$ at a few shallow spots to $459 \mathrm{~m}$ as deepest in the Landsort trench.

Transmission loss (TL) and reverberation levels (RL) were measured during a period of five days in May 2002. The two TL tracks, Run 9 and Run 11, and a circle covering the RL measured area are marked in the map (Fig. 2). Complementary bottom and oceanographic data were collected on a regular basis during all trials. The hydrology at the site was typical for the season. The summer thermocline had just started to develop at a depth of $30 \mathrm{~m}$, resulting in a sound channel at depth $60 \mathrm{~m}$ (Fig. 3).

Three vessels - WFS Planet (operated by FWG), MzB Schwedeneck (operated by Naval Test Center WTD 71) and 


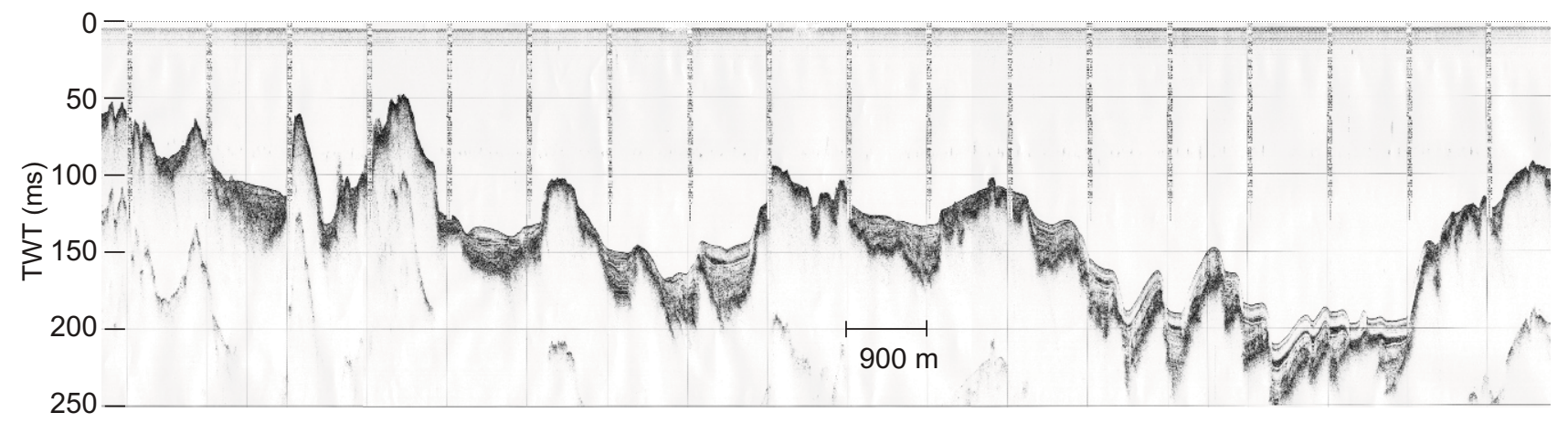

Fig. (1). This $16000 \mathrm{~m}$ long bottom section is representative for the test site. The bathymetry varies considerably with rocky outcrops and clay deposits in between. The depth is given as two-way travel-time (TWT).

HMS Urd (operated by FOI) were engaged in the experiment. WFS Planet was anchored at a center position and served as a platform for the receiving systems during the TL measurements and for the acoustic source system during the RL measurements.

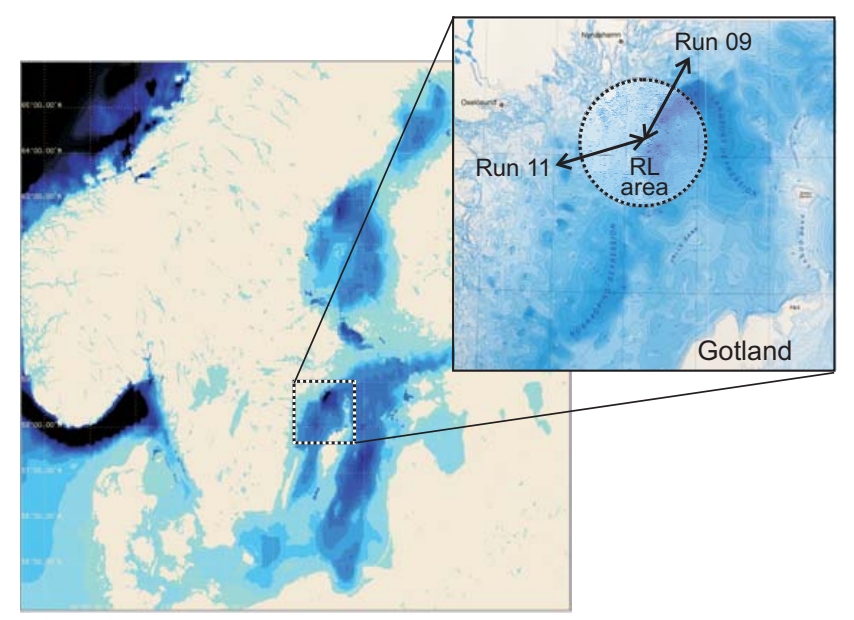

Fig. (2). Location of the site near the Landsort trench in the Baltic Sea. The two transmission loss tracks are marked as lines and the reverberation measurement area is indicated as a circle (Map from [6]).

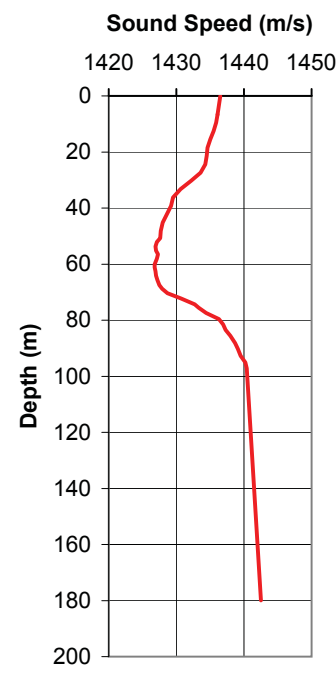

Fig. (3). Sound velocity profile recorded at the test site at the day of the experiment. A weak thermocline has started to develop at depth $30 \mathrm{~m}$, resulting in a sound channel at depth $60 \mathrm{~m}$.

\subsection{Transmission Loss Measurements}

The principle for the experimental arrangements is illustrated in Fig. (4). MzB Schwedeneck ran along tracks from or towards WFS Planet towing acoustic sources, covering the frequency range 500-5500 Hz. Sequences consisting of 22 different LFM and three CW (continuous wave) pulses were transmitted. The LFM pulses had bandwidths from 100 up to $2000 \mathrm{~Hz}$. The source levels varied between 190 and $203 \mathrm{~dB}$ re $1 \mu \mathrm{Pa}$ at $1 \mathrm{~m}$, among the three transducers in the source frame. The source depth was $35 \mathrm{~m}$ for Run 9 and 40 $\mathrm{m}$ for Run 11.

A vertical hydrophone chain receiving system was operated on board WFS Planet. It consisted of eight hydrophones, deployed at depths of 10, 20, 30, 40, 50, 60, 70 , and $90 \mathrm{~m}$.

At the beginning and at the end of each track, Conductivity Temperature Depth (CTD) profiles were taken from the transmitting and receiving ships. Along the TL tracks, the sound speed profiles were continuously logged with a $50 \mathrm{~m}$ long CTD chain which was towed by HMS Urd. The distance separation for the 51 CTD sensors in the chain was $1 \mathrm{~m}$.

\subsection{Reverberation Measurements}

The principle of the reverberation experimental arrangements is illustrated in Fig. (5), with $H M S$ Urd anchored close to WFS Planet at a distance of $450 \mathrm{~m}$. In principle this is a bistatic configuration, but compensation for the $450 \mathrm{~m}$ separation was needed only at the shortest recording ranges. Two omni-directional transmitters, covering the frequency bands $0.5-3 \mathrm{kHz}$ and $3-6 \mathrm{kHz}$, were operated from WFS Planet. The transmitters were deployed at depths $30 \mathrm{~m}$ and $35 \mathrm{~m}$, respectively. Seven types of LFM pulses with bandwidths from $100 \mathrm{~Hz}$ to $2 \mathrm{kHz}$ and pulse durations of 1 or $2 \mathrm{~s}$ were transmitted at source levels around $200 \mathrm{~dB}$ re $1 \mu \mathrm{Pa}$ at $1 \mathrm{~m}$.

The bottom scattered signals were received by an $11.6 \mathrm{~m}$ long horizontal array hanging under HMS Urd at a depth of $50 \mathrm{~m}$. The linear array was built up by 32 hydrophones, with intermediate distances of $0.375 \mathrm{~m}$ corresponding to a frequency limit of about $2 \mathrm{kHz}$. As a horizontal linear array has a starboard - port ambiguity, we recorded data with the 


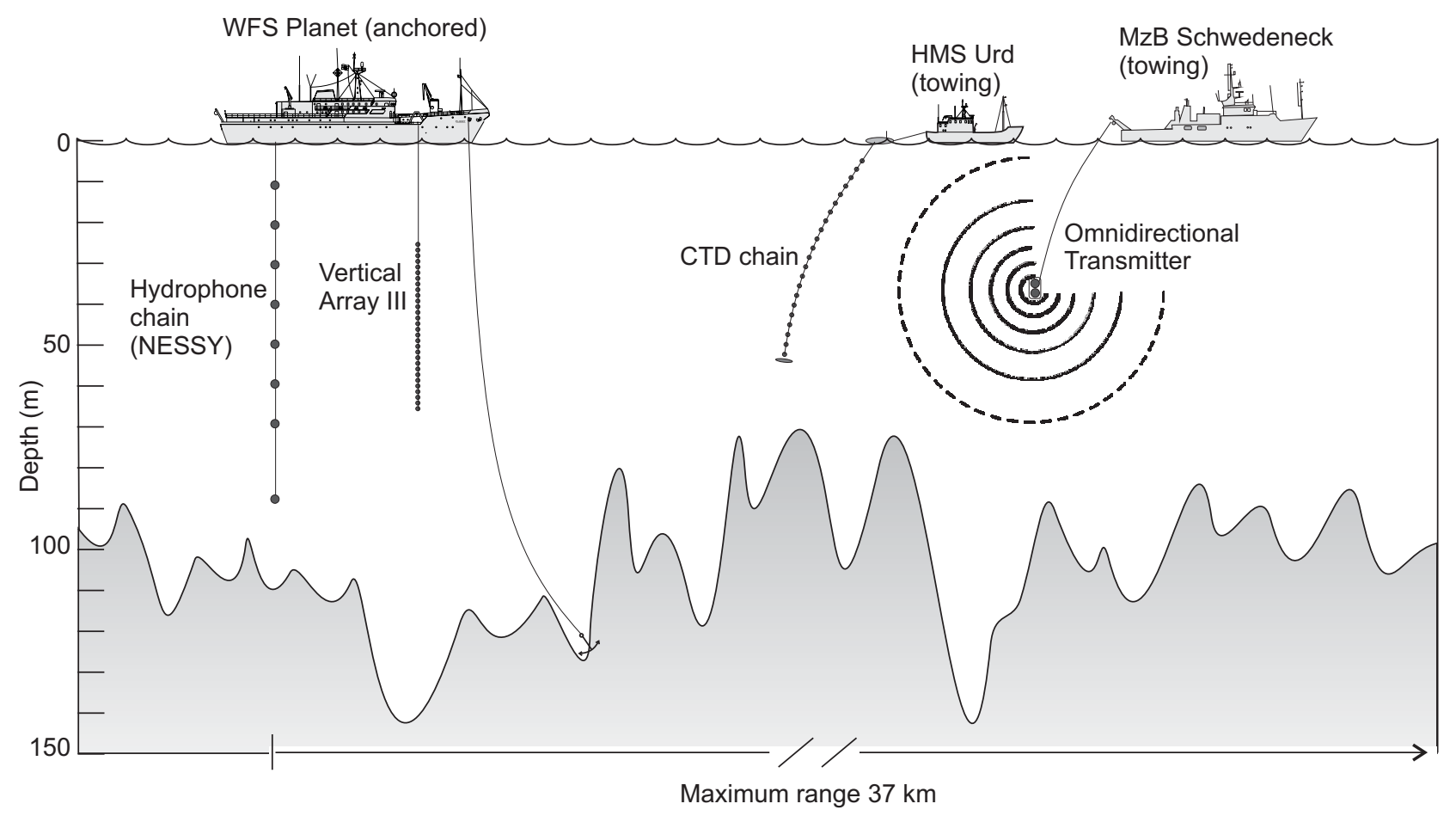

Fig. (4). Outline illustrating the transmission loss experimental arrangement.

array oriented in three directions differing up to 60 degrees, so that the ambiguity could be resolved.

Oceanographic and weather observations were recorded on both platforms. The sea state was around 2 during the experiment.

\section{THE SHALLOW-WATER SOUND CHANNEL}

With a source in the underwater sound channel (USC) in Fig. (3), sound is trapped in the channel where it is spread cylindrically without bottom interaction losses. Outside the USC, losses due to seabed scattering and absorption appear.

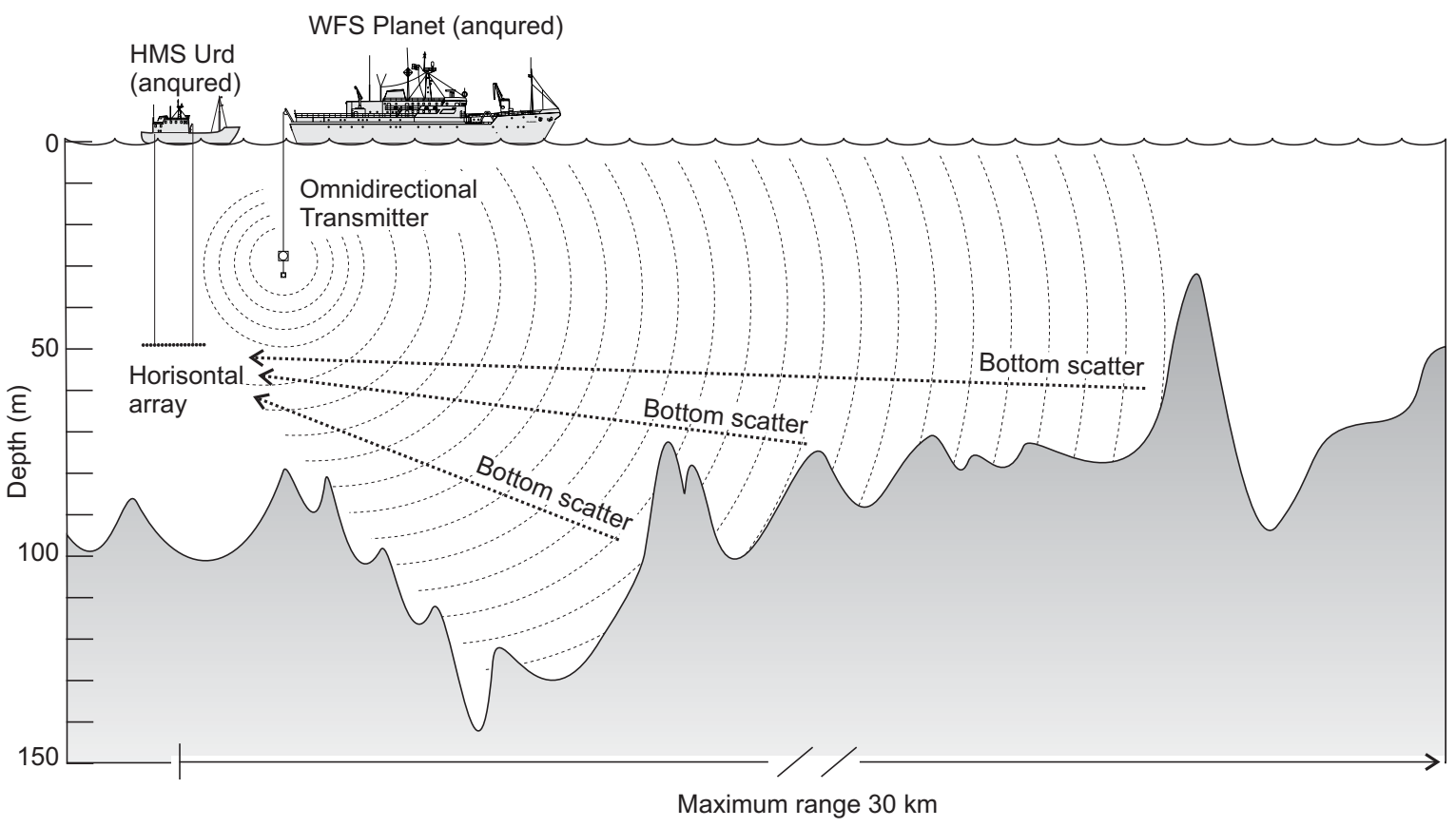

Fig. (5). Outline illustrating the reverberation measurements arrangement. 
For a quantitative illustration we consider a numerical example. The model is range-independent with $80 \mathrm{~m}$ of water above a homogeneous half-space bottom. We consider two bottom types, a soft one (clay) and a hard one (sand). The values for speed of sound $(\mathrm{km} / \mathrm{s})$, density $(\mathrm{g} / \mathrm{cc})$, attenuation (dB/wavelength) of the bottom are set to $1.5,1.6$, 0.5 in the soft case and to $1.8,2.0,0.7$ in the hard case. Seawater absorption is included according to the FrancoisGarrison formula [7] with the salinity 7 psu. Fig. (6) depicts computed TL as functions of depth at the ranges 10 and 30 $\mathrm{km}$ for a $1 \mathrm{kHz}$ source at depth $40 \mathrm{~m}$. The particular sound speed profile, of the same type as in Fig. (3), is also shown.

The TL was computed by a normal-mode program using an incoherent summation of modes [8, p. 275]. At the axis of the USC, the intensities are almost the same for the soft and hard bottom cases. The drop in TL from 10 to $30 \mathrm{~km}$ at mid depth is around $5 \mathrm{~dB}$ corresponding to cylindrical spreading.
However, the loss increases away from the axis and its magnitude depends on the bottom. At the depth $10 \mathrm{~m}$, for example, the drop is 6.5 and $11.5 \mathrm{~dB}$ for the hard and soft bottoms, respectively. The graphs in Fig. (6) indicate that the influence of the sound velocity profile is less for a hard bottom than for a soft one. This feature is readily explained by a modal analysis. There are 68 and 33 trapped modes in the hard and soft cases, respectively. In both cases, the phase velocities of the first 17 modes are practically the same and they span the range $1425-1450 \mathrm{~m} / \mathrm{s}$. Their attenuation rates expressed in $\mathrm{dB} / \mathrm{km}$ are displayed in Fig. (7).

The decay of the first seven modes is less than 0.05 $\mathrm{dB} / \mathrm{km}$ in both cases. These modes have phase velocities $1425-1436 \mathrm{~m} / \mathrm{s}$ and their interaction with the sea and bottom surfaces is very slight. They are trapped at mid-water depths in the USC and propagate to long ranges irrespective of the bottom conditions. As the modal phase velocities increase,
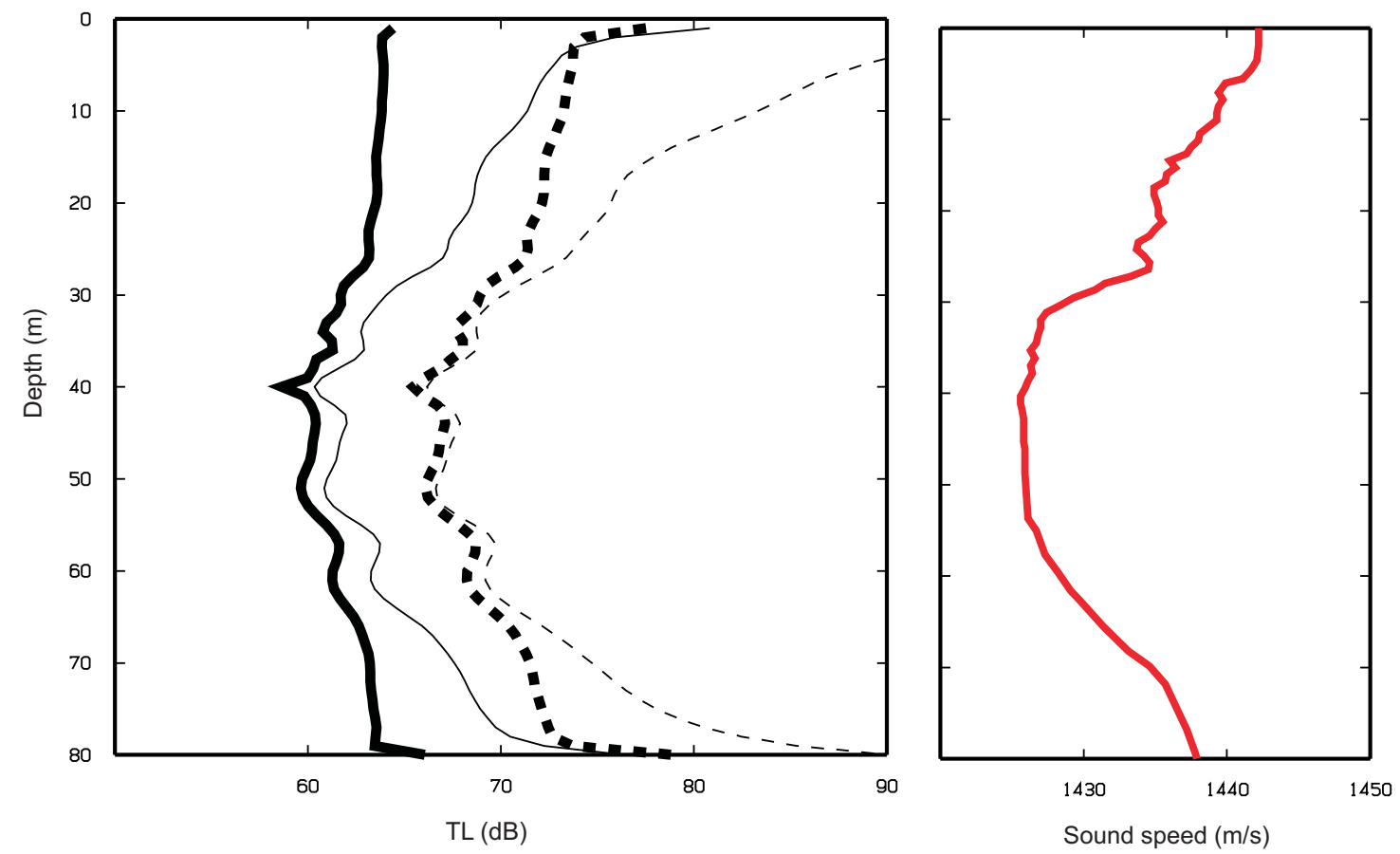

Fig. (6). Left: TL at the ranges 10 (solid lines) and $30 \mathrm{~km}$ (dashed lines) for the hard (thick) and soft bottom (thin) as functions of depth. The source depth is $40 \mathrm{~m}$ and the frequency $1 \mathrm{kHz}$. Right: the sound velocity profile.

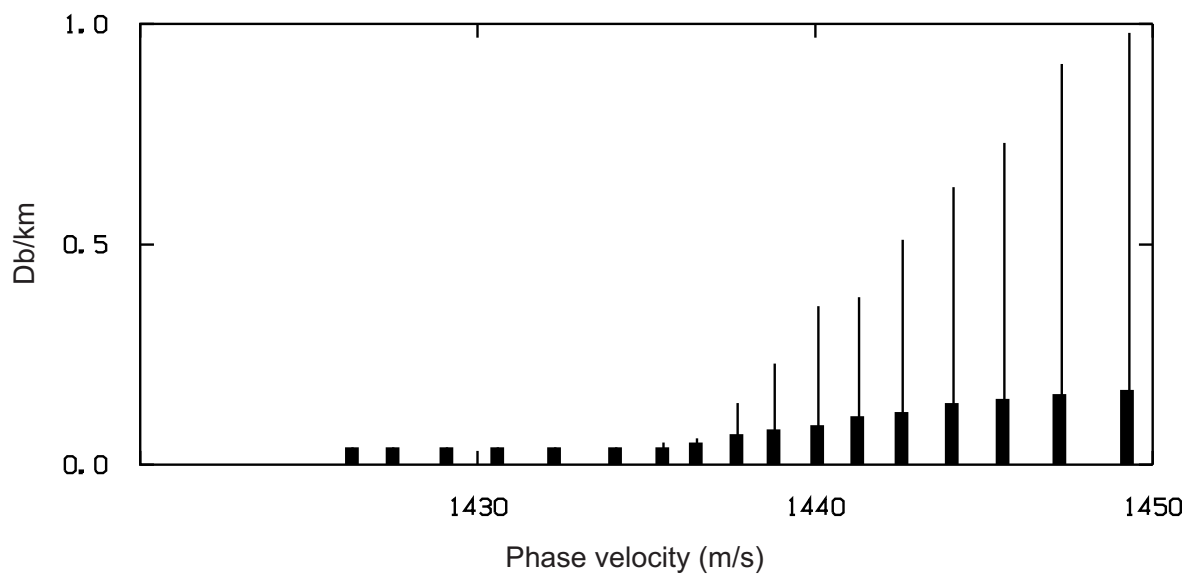

Fig. (7). The attenuation rates expressed in $\mathrm{dB} / \mathrm{km}$ of the first 17 modes for a soft bottom (thin staples) and a hard bottom (thick staples). The attenuation of the first seven modes with phase velocities between 1425 and $1436 \mathrm{~m} / \mathrm{s}$ is less than $0.05 \mathrm{~dB} / \mathrm{km}$. 
the modes start to span the whole water column. They are analogous to rays which bounce back and forth between the sea surface and the bottom. As seen in Fig. (7), the decay rates of modes 8-17 are much larger for the soft bottom despite that the attenuation coefficient of the bottom is less. However, at total reflection the modal penetration depth decreases when the velocity contrast is increased, and it is the combined effect of penetration and attenuation coefficient that determines the decay rate of the waterborne signal. The mode stripping process is more effective for a soft bottom and it can be used as a discriminatory feature for bottom classification.

The intensity is high even at the upper and lower receivers in Fig. (6), as compared to the case (not shown) with a sound speed profile with a negative gradient from the sea surface to the bottom. The reason is that the grazing angles of rays at the water/sediment surface are smaller for an upward refracting profile in bottom waters than for a downward refracting one.

The optimal frequency for long-range propagation in the sea has been studied in $[7,9,10]$ for various environmental conditions. In short, it was found that for water depths around $100 \mathrm{~m}$ and with a source and a receiver at mid-depth, the optimum frequency range is $200-400 \mathrm{~Hz}$. Mostly, these investigations have been limited to isovelocity or downward refraction propagation conditions.

Our experimental results (see Section 6) indicate that the optimum frequency range is higher in the presence of an USC, even for near surface or bottom receivers. The experimental findings are well supported by normal-mode solutions of the soft bottom case of the model described above. Fig. (8) shows isoloss contours in the frequency/range plane for a receiver at the depth $10 \mathrm{~m}$ and the source at $40 \mathrm{~m}$. We note that the transmission loss even outside the USC is low over a broad range of frequencies, with a minimum around $2.3 \mathrm{kHz}$ (Fig. 8).

The good propagation conditions at higher frequencies made possible by the USC for water depths larger than $70 \mathrm{~m}$ also lead to high ambient noise levels and long reverberation times. For example, in the current experiment (sea state 2) the spectral noise level at $2 \mathrm{kHz}$ was measured to $70 \mathrm{~dB}$ re 1 $\mu \mathrm{Pa} /(\mathrm{Hz})^{1 / 2}$. This should be compared to the corresponding Wenz curve value [11, p. 213, figure 7.8], which is only 45 $\mathrm{dB}$ re $1 \mu \mathrm{Pa} /(\mathrm{Hz})^{1 / 2}$.

\section{DATA ANALYSIS}

\subsection{Transmission Loss Analysis}

The transmission loss analysis was performed on data recorded with the vertical hydrophone chain. At first, the signal from each hydrophone was filtered with an incoherent matched filter [12], and only the envelope is studied. The arrival time for each pulse was determined from hydrophones at depth $40 \mathrm{~m}$ (Run 11) or $50 \mathrm{~m}$ (Run 9), which were positioned in the sound channel and had the best signalto-noise ratio. The squared matched filtered signal was integrated around the arrival time of the pulse with a window length depending on the bandwidth, see Table 1. The noise level was estimated, by integrating the matched filtered signal in an interval prior to the pulse, and removed. If a negative value was obtained after noise subtraction, it was removed from the analysis. A nonnegative value was compared with the corresponding integral for a matched filtered source pulse and the desired transmission loss estimate was obtained.

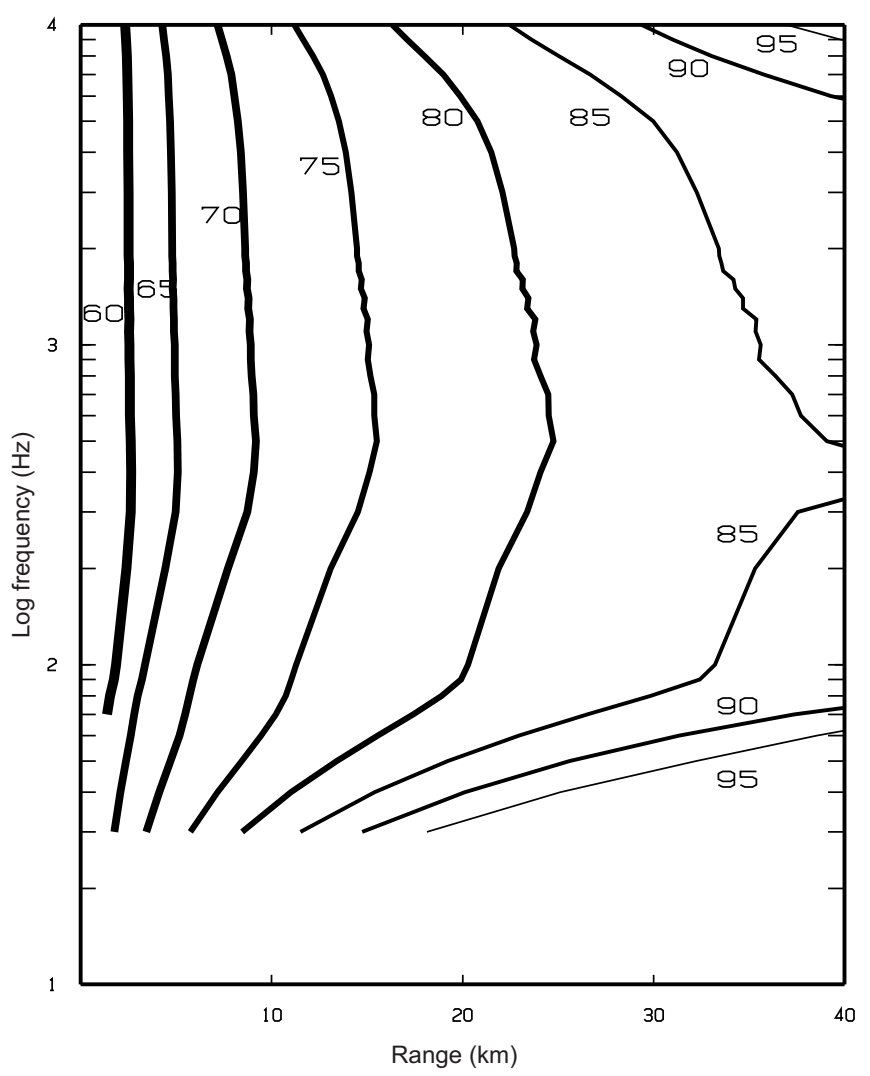

Fig. (8). Transmission loss as a function of range and frequency given as isoloss contours for $60,65, \ldots, 95 \mathrm{~dB}$ from left to right. The bottom is soft (clay), and the source and receiver depths are 40 and $10 \mathrm{~m}$, respectively.

Table 1. Time Window Used for Integration

\begin{tabular}{|c|c|c|}
\hline Bandwidth (Hz) & Time Before Pulse (s) & Time After Pulse (s) \\
\hline \hline 100 & 0.1 & 0.6 \\
\hline 200 & 0.05 & 0.3 \\
\hline $400,1000,2000$ & 0.025 & 0.15 \\
\hline
\end{tabular}

For the three continuous wave pulses, matched filtering was not a satisfactory analysis method. Instead, spectral analysis was employed. The nonparametric multitaper method, implemented in the Matlab function pmtm [13] was used for calculating the frequency spectrum. The arrival time was determined from a strong adjacent LFM pulse as in the LFM case, and a suitable time window was chosen for spectral analysis. Each power spectrum was integrated \pm 20 $\mathrm{Hz}$ around the frequency of the pulse. The background noise 
was estimated from spectral levels below and above the pulse frequency, and subtracted.

Spectral analysis with noise subtraction was tried for the LFM pulses as well. For strong signals, the matched filter results were reproduced. For weak signals, the two methods were less consistent, with one method occasionally providing better results than the other. All results for LFM pulses presented in the paper are from matched filter analysis.

\subsection{Reverberation Data Analysis}

The reverberation analysis was performed on data from the horizontal array. First, the data were beamformed using a general time-domain interpolation beamformer with an interpolation factor of 5 [14]. The directions of the calculated beams were chosen to be linear in $\sin (\varphi)$, where $\varphi$ is the angle of the beam relative to the array, in order to keep the scalloping loss below $3 \mathrm{~dB}[14,15]$. Next, the beam signals were matched filtered [12] and normalized (see Section 5.3). The measured reverberation levels versus range are presented in A-scans, with corrections for hydrophone gain, filter gain and directivity gain.

\section{MODELLING TOOLS}

\subsection{Forward Computational Models}

The TL data were inverted for bottom type parameters with MOCASSIN as the forward model. MOCASSIN is an acronym for the German words Monte Carlo Schall Strahlen Intensitäten. It is a ray trace model for transmission loss and monostatic reverberation that has been developed by H.G. Schneider [1]. Rays are traced within the water column along circular arcs, as prescribed by a piecewise linear sound speed profile.

The bathymetry is represented by a number of linear bottom segments, and each segment can be classified according to nine predefined hardness types. The softest bottom type, 1, corresponds to mud/clay, and the hardest type, 9 , corresponds to coarse sand with gravel/rock. When a ray hits the bottom, it is reflected with a reflection coefficient that is determined by the pertinent bottom segment type, the incidence angle, and the frequency. Reflection loss at the bottom will increase with increasing frequency.

A characteristic feature of MOCASSIN is that rays are allowed to change directions stochastically in order to mimic effects of diffraction and fine scale details in the water sound speed profile, for example, that have not been explicitly modeled. A bubbly surface layer can be included, with additional loss. Monostatic reverberation is modeled by combining transmission loss in both directions with scattering at the bottom and/or at the surface. Angledependent bottom scattering may be calculated according to Lambert's law, but alternatives including dependence on bottom segment type and frequency are also available.

The original version of MOCASSIN does not allow for a range-dependent sound speed profile. Since such range dependence was deemed essential for modelling the BAROC experimental results, we have developed a multiple-profile version. The range interval is divided into sectors, where each sector has its own range-independent sound speed profile. When a ray enters a new sector, its direction is changed according to Snell's law, but reflections at the vertical sector boundaries are not included. A convenient input data handling is obtained by combining the profile sectors with the bottom segments. A number of range intervals are specified, each with its particular bottom segment and sound speed profile types. Dynamic memory allocation is used to allow an arbitrary number of range intervals, for example.

Additional computations were made with the wide-angle parabolic wave equation model JEPE [16, 17]. This model is applicable to range-dependent environments provided that the propagation angles are less than some 36 degrees. This condition is monitored by JEPE as the computations proceed, and in the present application it was found to be well satisfied. In a deterministic environment, JEPE gives more accurate results than MOCASSIN, but it is too slow to be used for inversion of long-range data in the $\mathrm{kHz}$ regime. Prior to the analysis of TL data, however, it was run together with MOCASSIN on several relevant cases. The computed TL levels were found to be consistent.

\subsection{Genetic Inversion}

In developing our version of the genetic algorithm [18], we have mainly followed [19] and [20]. Genetic algorithms may differ in the way the three genetic operators reproduction, crossover, and mutation are applied. Our version is characterized by steady-state reproduction with rank-based selection of parents and worst-member replacement, single-point crossover implemented so as to remove dependence on the order in which the different parameters are encoded in the chromosomes, adaptive mutation, and distributed populations. Three initially uncorrelated populations are maintained.

Our particular fitness function was the average absolute value of the difference in $\mathrm{dB}$ between the measured TL data and the outputs from calculations with the MOCASSIN model [1]. All genetic algorithm trials were concluded by local optimization using Rosenbrock's method [21]. This is a simple line-search method for non-linear optimization, which, unlike the Gauss-Newton approach, does not need the computation of the gradient of the fitness function.

In the inversion, we constructed a chromosome of the range dependent bottom parameters, as defined in the MOCASSIN model. Each range segment was assigned a bottom hardness value of $1-9$, but with the value 8 omitted to allow a representation with three bits.

The number of parameters was chosen by a careful analysis of the bottom topography. At first, the bottom for each run was divided into parts. The bottom segments in each part were sorted by their gradients and binned. The bin sizes were chosen to produce approximately the same number of range segments in each bin. Finally, the range segments in each bin were given the same hardness value in the inversion. 
For Run 9 we used three parts with nine bins in each, i.e., a total of 27 bins giving a chromosome with 81 bits. For Run 11 we used five parts with five bins in each, producing 25 bins and 75 bits in the chromosome.

\subsection{Reverberation Modelling}

The matched filtering of reverberation data was performed as a correlation with the analytic signal of the transmitted LFM pulse. Normalization was performed in order to preserve the peak level from an ideal echo. We elaborate a bit on this point and denote a unit amplitude pulse by $s(t)$, where $t$ is time. In order to preserve the peak level of an ideal echo, the correlation of $s(t)$ with its analytic signal must be scaled with the factor $2 / T$, where $T$ is the pulse time. We denote the scaled cross-correlated waveform by $\varphi(t)$. The MOCASSIN model assumes a source pulse of effective value one. In order to model the reverberation, we need to assess the change in level when the source waveform is changed from $s(t)$ to $\varphi(t)$. Reverberation power is proportional to the squared $\mathrm{L}^{2}$ norm of the source waveform. Assuming that $T B$ is large, where $B$ is the bandwidth of $s(t)$, some appropriate approximations and calculations provide the estimate

$\int|\varphi(t)|^{2} \mathrm{~d} t=1 / B$.

It follows that our normalized matched filtering will lower the bandpass filtered reverberation traces by 10 $\lg (B T / 2) \mathrm{dB}$, and this is precisely what was observed when processing the experimental data.

The reverberation computations with MOCASSIN are performed assuming azimuthal symmetry and an omnidirectional illumination horizontally. The horizontal array used during the BAROC reverberation measurements implies horizontal focusing, and the modelling results have to be adjusted accordingly. Since the essential rays are not uniformly distributed in the vertical direction, a bias for horizontal rays seems natural. Such a bias is included by replacing the sinc function in the array directivity formula [15, Eq. 11-39] with a zero order Bessel function.

\section{RESULTS}

\subsection{Measurements at Run 9 and at Run 11}

The measured sound speed profiles and the bathymetries for Run 9 and Run 11 are shown in Fig. (9). Significant variations can be noted. As a result, recorded TL levels show large fluctuations with distance. To simplify the analysis, we have smoothed the TL curves by fitting 7th or 10th degree polynomials. The bottom does not interfere with the USC, except at some sea mount peaks.

For the modelling, the bathymetry has been represented by 130 bottom segments for Run 9 , and 200 segments for Run 11. The ability to use multiple sound speed profiles in MOCASSIN enabled us to incorporate the CTD chain data. However, in order to make the calculations tractable, we picked only one profile per $\mathrm{km}$ from each original set of around 350 profiles.

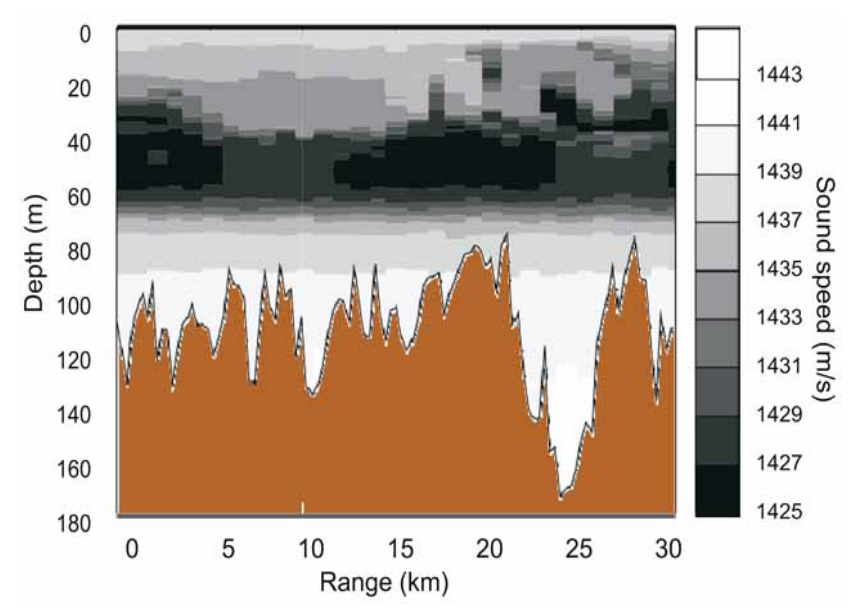

Fig. (9a). The sound speed profiles and the bathymetry measured at Run 9.

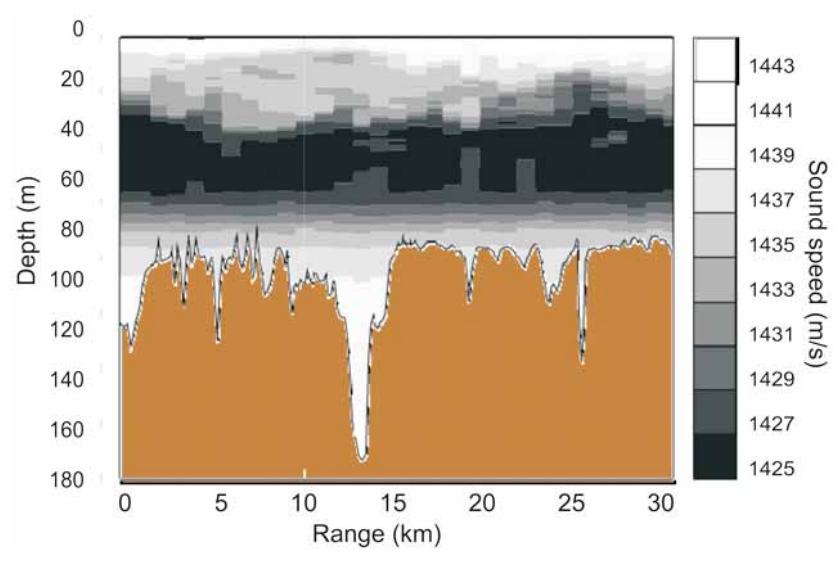

Fig. (9b). The sound speed profiles and the bathymetry measured at Run 11.

\subsection{Transmission Loss Results}

Fig. (10), right panel, shows measured and averaged TL for Run 9 at the frequency $3700 \mathrm{~Hz}$ with the source at the depth $35 \mathrm{~m}$. A clear channel effect can be seen, but the intensity outside the USC is still rather high. The loss between 10 and $30 \mathrm{~km}$ at the axis of the USC is around 10 $\mathrm{dB}$, while the corresponding loss increases to $20 \mathrm{~dB}$ at the top and bottom receivers. The geometrical loss of cylindrical spreading over this range is $5 \mathrm{~dB}$, while sea water absorption amounts to $3 \mathrm{~dB}$. Outside the USC, the remaining loss can largely be attributed to scattering and absorption by the bottom. In the USC, a plausible explanation is channel leakage due to variations of the sound speed profile with range. For a lossy bottom, the process is partly irreversible and it leads to a larger TL as compared with rangeindependent conditions [22-24]. Fig. (10), left panel, shows TL for $750 \mathrm{~Hz}$. The picture is quite similar to the $3700 \mathrm{~Hz}$ case, although the intensity levels are somewhat lower.

Corresponding modelling results are presented in Figs. $(\mathbf{1 1}, 12)$. Fig. (11) concerns genetic algorithm inversion with MOCASSIN calculations. The same overall range-depth dependence can be observed, as compared to the experimental results in Fig. (10). However, the computed TL was generally a few $\mathrm{dB}$ lower. In particular, the USC was 
wider in the model runs than in the experiment. The inversions were made for one frequency at the time, using data from all depths.

The computed hardness values are depicted in Fig. (13). TL data at different frequencies were inverted separately, giving a distribution of hardness values at each range. This distribution is visualized by a colour coding where the darkness is proportional to the number of obtained hardness values. For Run 11, the computed hardness values are somewhat more consistent among the different frequencies than for Run 9. Areas with sharp peaks in the bathymetry are harder, see the initial part in Fig. (13b), for example. Areas with a more horizontal bathymetry are softer, e.g. at 13-20 km in Fig. (13b).

For each run, the mean bottom hardness values over all ranges and all frequencies were calculated. These mean

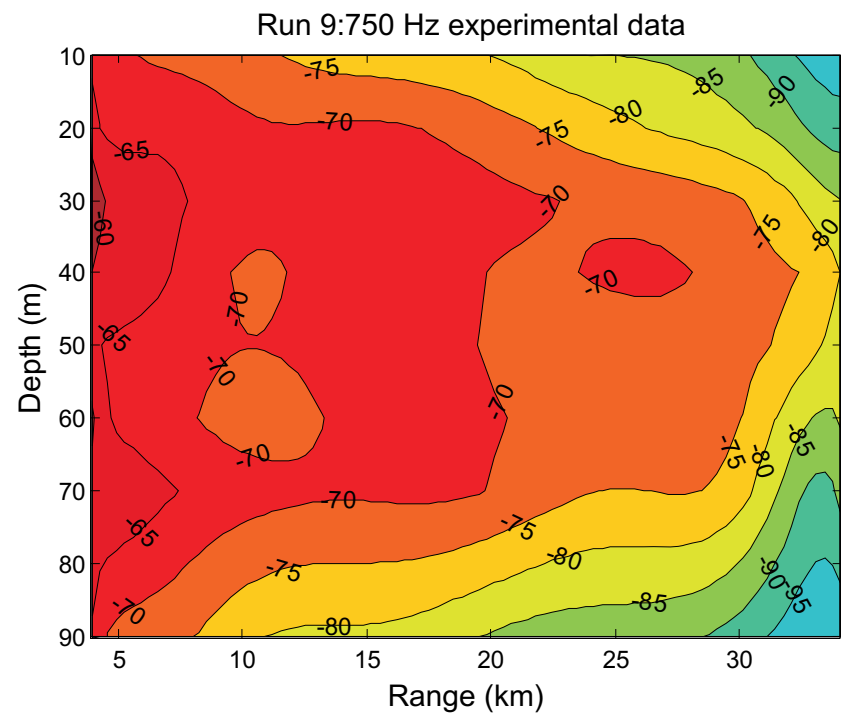

hardness values were then converted to porosity [1], giving a porosity value of $58 \%$ for Run 9 and $61 \%$ for Run 11 . Such values correspond to a sediment velocity at the seafloor which is about the same as the water sound speed [25]. In order to model our experiment with the JEPE model, we have defined a sediment layer with the thickness $5 \mathrm{~m}$ overlying a basement with the bedrock parameters $5.5 \mathrm{~km} / \mathrm{s}, 2.6 \mathrm{~g} / \mathrm{cc}, 0.15$ $\mathrm{dB} /$ wavelength (for sound speed, density and attenuation, respectively). Guided by the results of the inversion based on ray modelling, the velocity of the sediment of Run 9 was set somewhat higher than for Run 11. After a few runs by JEPE for various sediment parameters, it was found that $1.45 \mathrm{~km} / \mathrm{s}, 1.5$ $\mathrm{g} / \mathrm{cc}, 0.5 \mathrm{~dB} /$ wavelength, for Run 9 , and $1.4 \mathrm{~km} / \mathrm{s}, 1.5 \mathrm{~g} / \mathrm{cc}, 0.5$ $\mathrm{dB} /$ wavelength, for Run 11, furnished good fit with the experimental TL data (Fig. 12).

Our experimental TL data indicate that the frequency dependence in the range $0.5-5 \mathrm{kHz}$ is slight at all receivers.

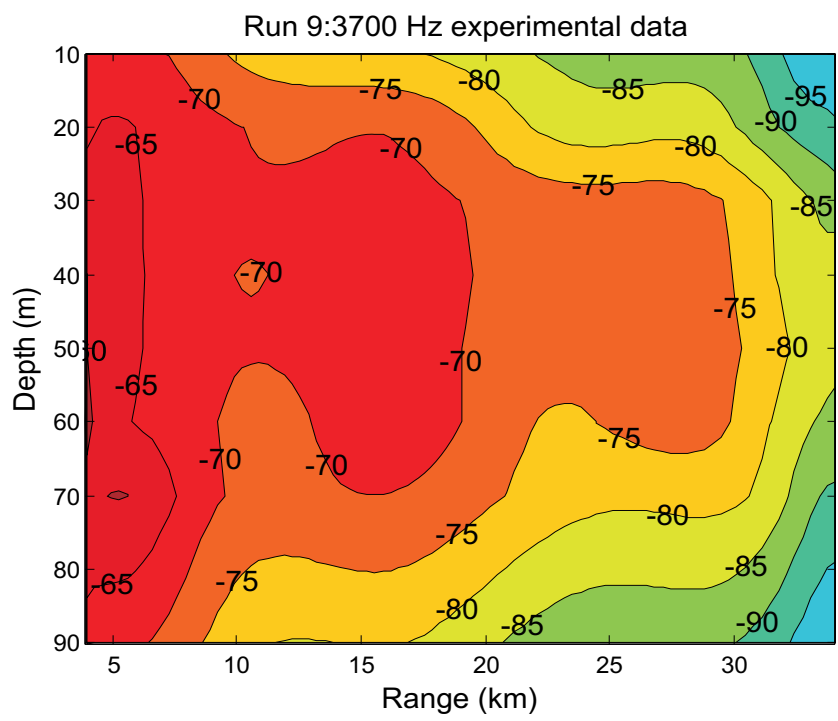

Fig. (10). Contour plot of experimental transmission loss versus range and depth from Run 9. The source depth is $35 \mathrm{~m}$ and the frequency $750 \mathrm{~Hz}$. Left: $750 \mathrm{~Hz}$, right: $3700 \mathrm{~Hz}$
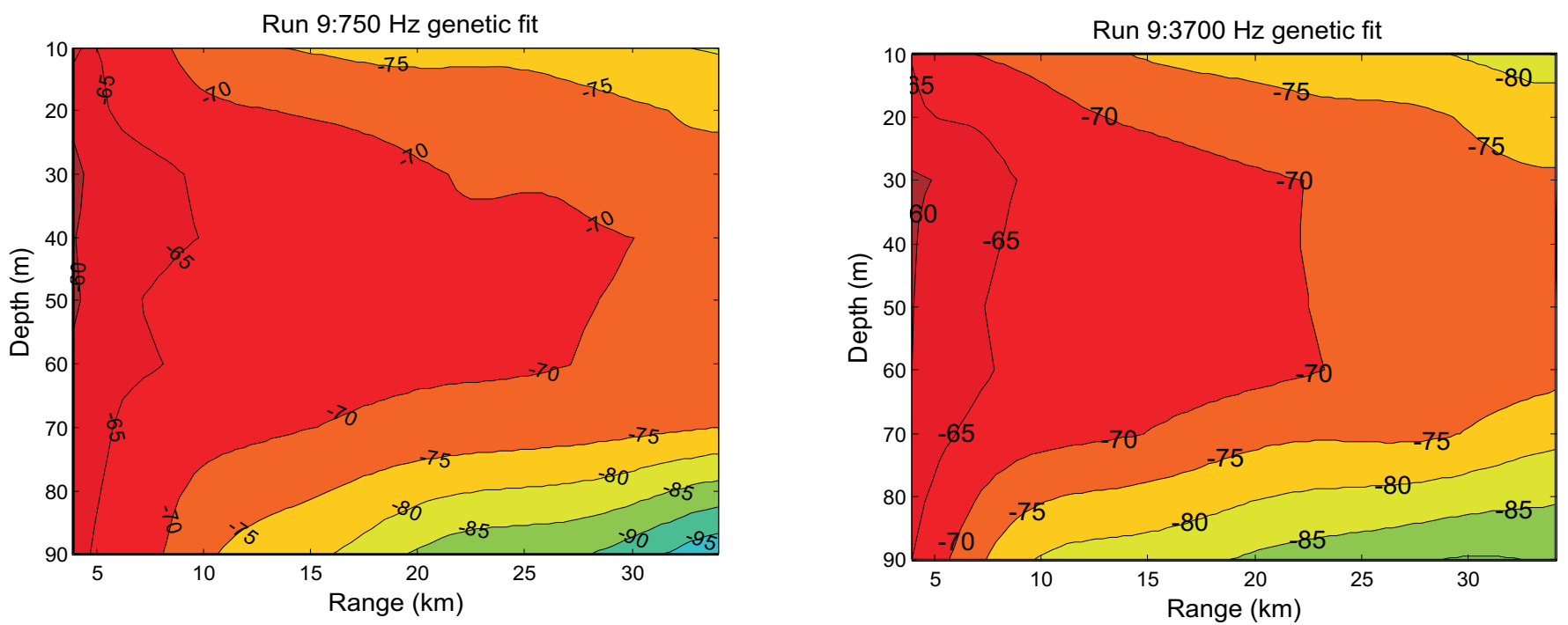

Fig. (11). Contour plot of the result of genetic algorithm inversion, of the experimental data in Fig. (10) above. The mean fit is $3.3 \mathrm{~dB}$ for $750 \mathrm{~Hz}$ (left) and $3.5 \mathrm{~dB}$ for $3700 \mathrm{~Hz}$ (right). 

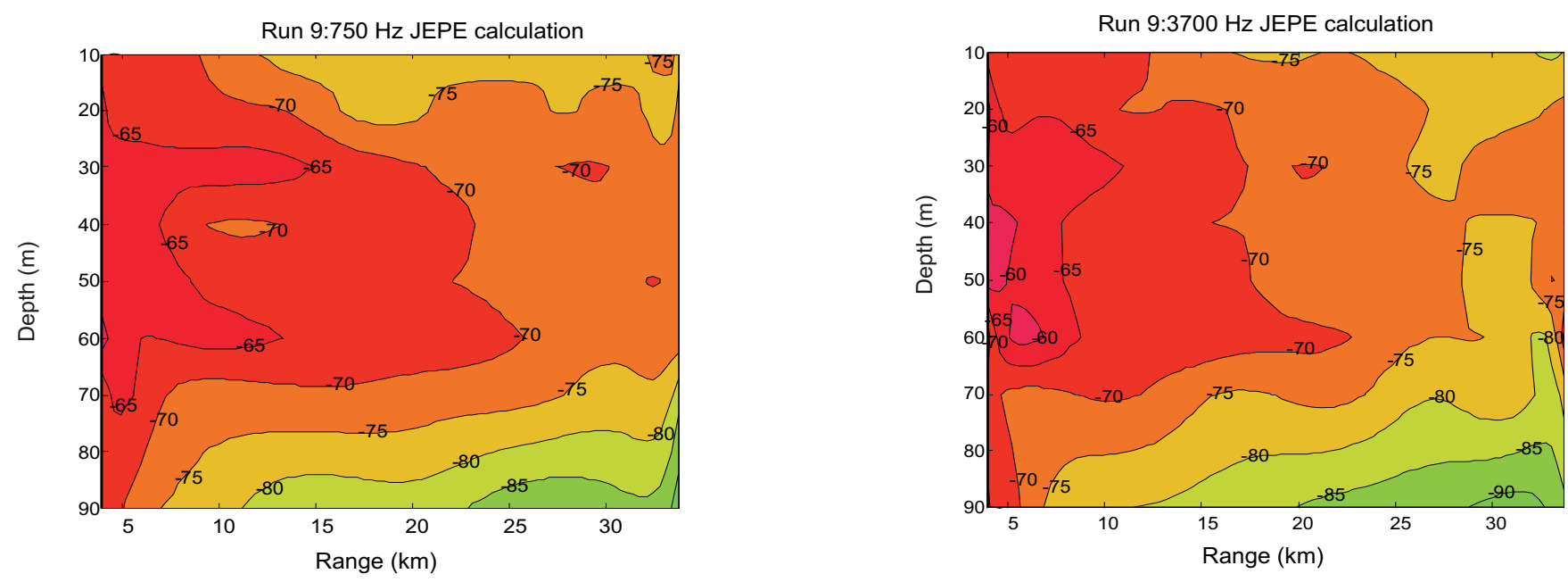

Fig. (12). Contour plot of the result of calculations with the JEPE model. The mean fit is $3.5 \mathrm{~dB}$ for $750 \mathrm{~Hz}$ (left) and $3.7 \mathrm{~dB}$ for $3700 \mathrm{~Hz}$ (right).
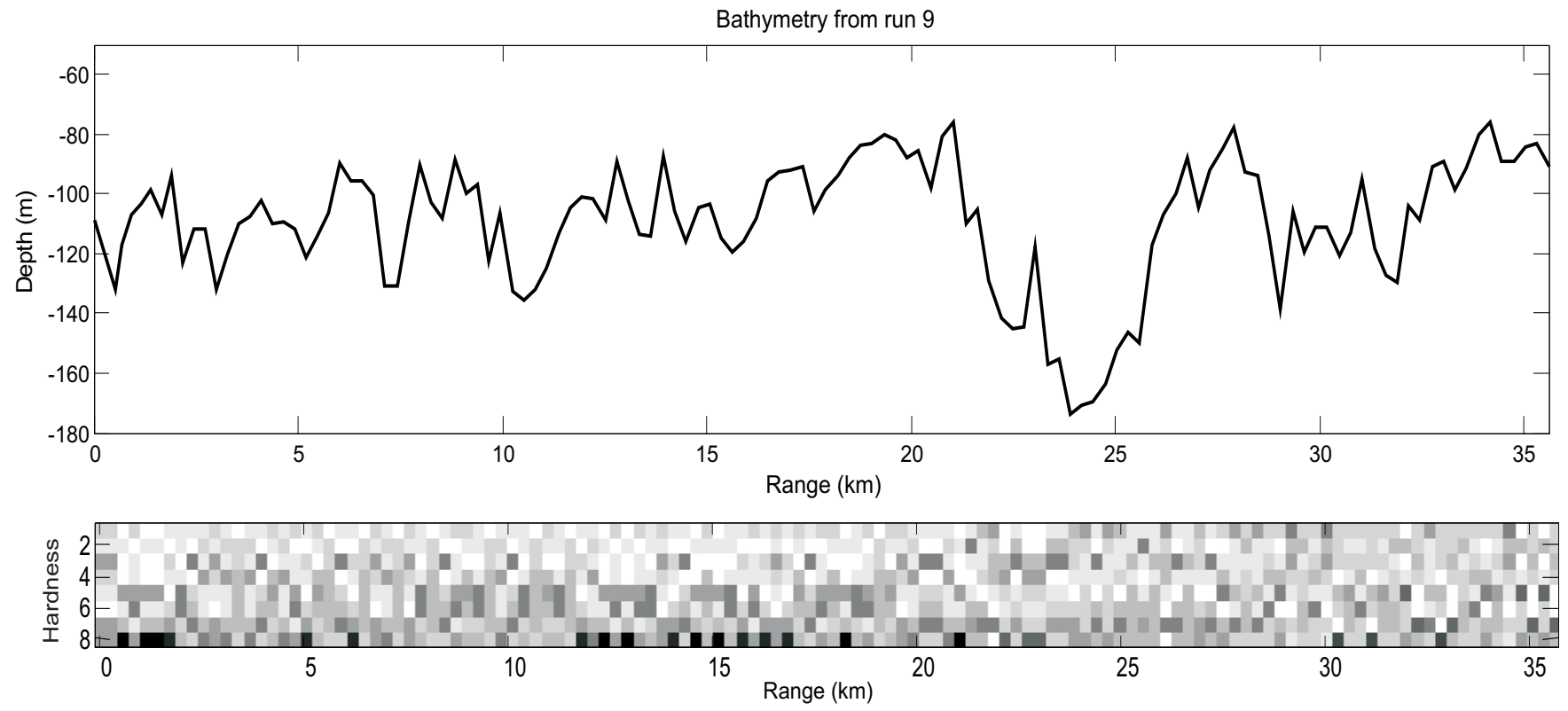

Fig. (13a). Bathymetry (top) and bottom hardness values (bottom) from genetic inversion of Run 9 TL data. Data at different frequencies were inverted separately, and the darkness of each pixel is proportional to the number of times the corresponding hardness value appeared for the corresponding bottom segment.

For example, Fig. (14), left panel, depicts TL in the range/frequency plane recorded at Run 9 with the deepest receiver at $90 \mathrm{~m}$. The corresponding contour plot for Run 11 is shown in the right panel. The intensity increases slightly with frequency for Run 11. A frequency of about $4 \mathrm{kHz}$ appears to have the lowest TL for both runs. In addition, low TL can be noted for around $800 \mathrm{~Hz}$ in Run 9.

Inside the sound channel, at depth $30-60 \mathrm{~m}$, the frequency dependence is even weaker, with low losses at all frequencies, as discussed in Section 3. To study the influence of the sound channel in more detail, the TL for the hydrophones at depths 40 and $50 \mathrm{~m}$ were averaged for each range, and the differences to the TL at depths 10 and $90 \mathrm{~m}$ were calculated. This was done for all 25 pulses, and the results were averaged and plotted in Fig. (15). The values plotted demonstrate the average influence of the sound channel on the TL for the two runs. The increase in TL outside the sound channel is substantially larger for Run 11 than for Run 9. According to the modal analysis in Section 3, this indicates that the bottom is softer for Run 11 than for Run 9. This suggestion is also supported by our inversion results. 

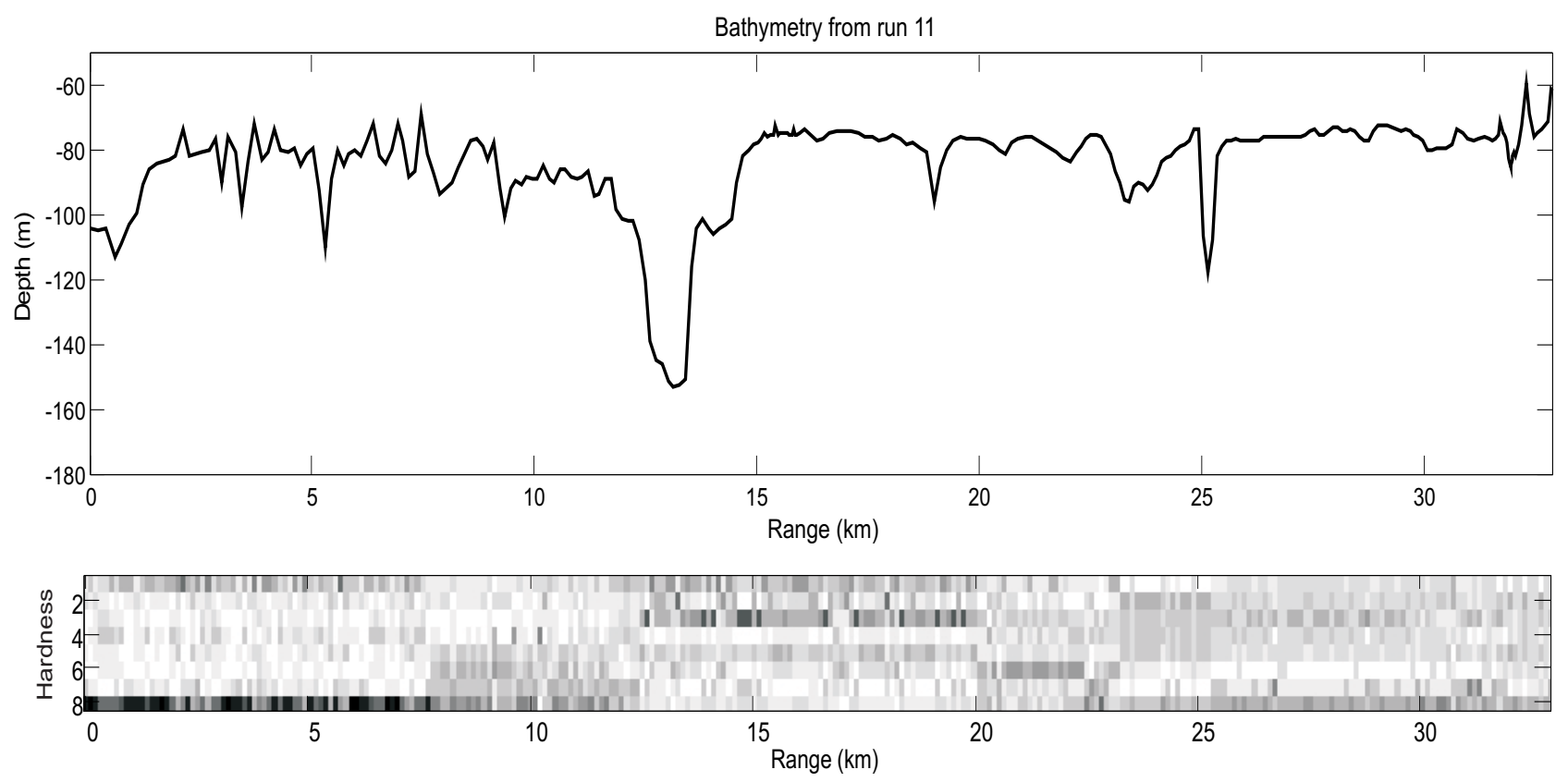

Fig. (13b). As Fig. (13a) but for Run 11 .
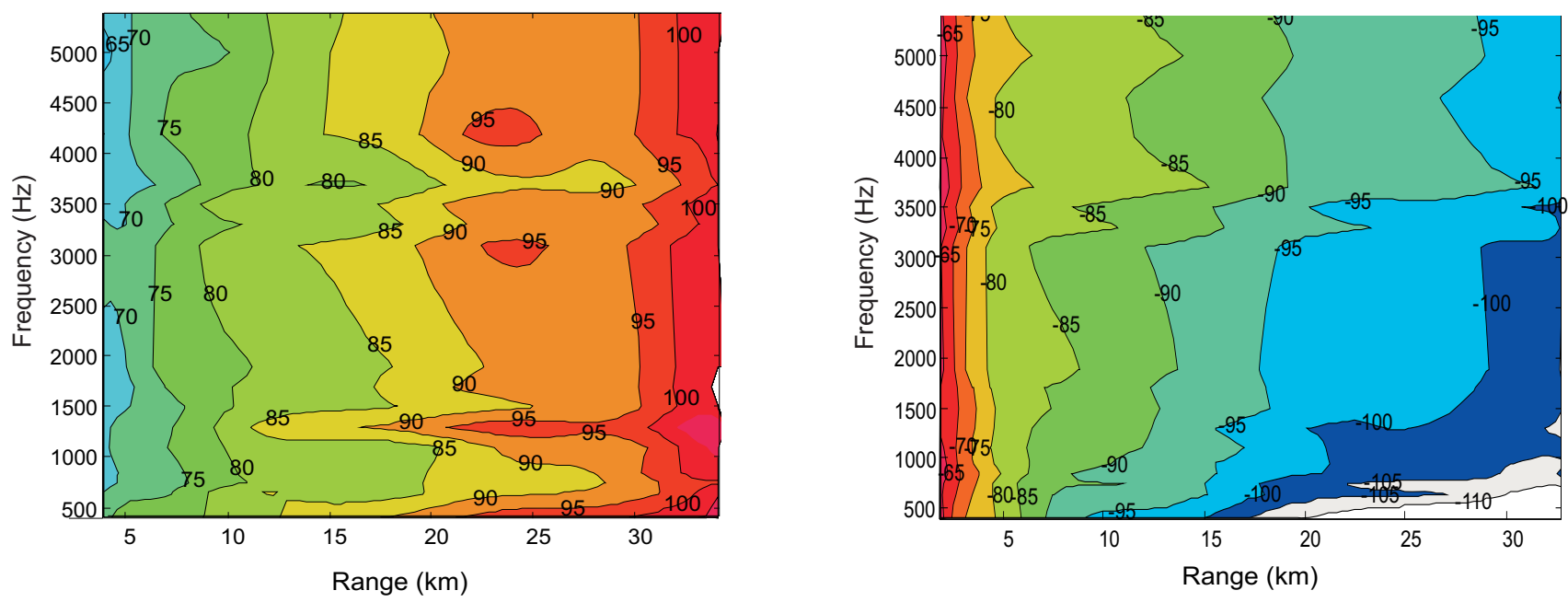

Fig. (14). Experimental transmission loss as functions of frequency and range for Run 9 (left) and Run 11 (right). The receiver is at depth 90 $\mathrm{m}$.

\subsection{Reverberation Results}

The bottom topography at the Landsort site is complicated, with peaks of crystalline outcrops and trenches with sediment deposits in between. The dominant part of the reverberation was anticipated to be produced by the bottom. Indeed, the RL measurements indicate a clear correlation between the topography and RL. Similar results have been reported earlier [11, Sec. 8.13] and [26]. The correlation is illustrated in Figs. $(\mathbf{1 6}, \mathbf{1 7})$, where three different bottom cross-sections are compared with the corresponding measured reverberation (A-scans) received from a 1.0-2.0 kHz LFM pulse.

Fig. (16) shows results with horizontal receiver array beamforming in a NNE direction close to Run 9. NNE is directed west 10 degrees from Run 9 in Fig. (2). A ridge with outcrops and sea mounts appear at the bottom, causing enhanced bottom reverberation at $7-12 \mathrm{~km}$ range. Local structures causing highlights in the reverberation can be seen at 15 and $22 \mathrm{~km}$.

Fig. (17) shows corresponding results with beamforming in the Run 9 and Run 11 directions, respectively. Concerning 
physical orientation of the array, the two cases represent a broadside and an endfire situation, respectively, and the implied difference in horizontal directivity must be taken into account in the modelling. The outcrops in these two directions are not as high, and the variations in bottom reverberation are smoother than for the NNE direction. The noise level appears to be reached beyond the range of about $7 \mathrm{~km}$.

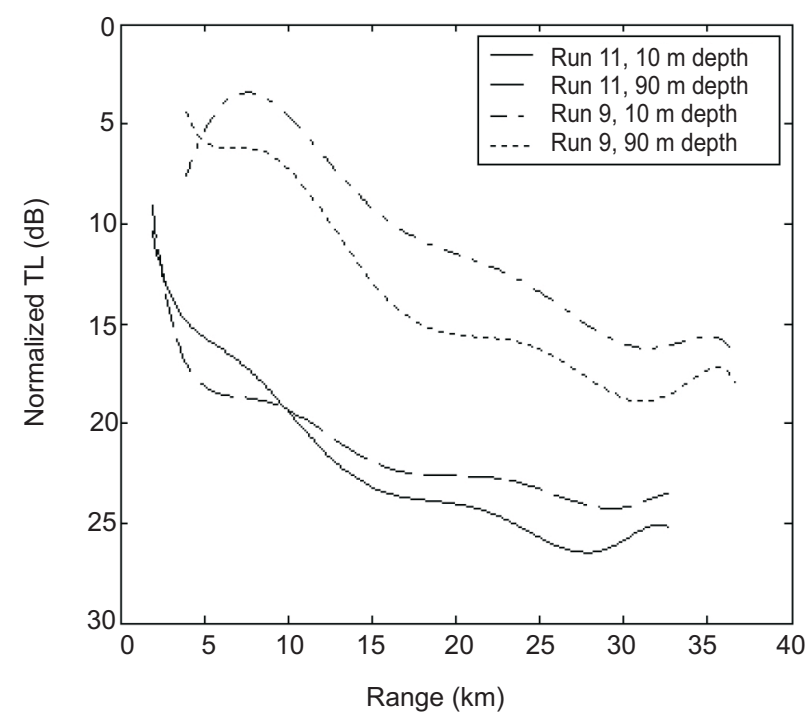

Fig. (15). Average influence of the sound channel on TL for the two runs. The curves show incremental TL, as related to the corresponding TL at depths 40 and $50 \mathrm{~m}$ in the USC.

For the Run 9 and Run 11 directions, range-dependent sound speed profiles and bottom parameters are readily available from the TL measurements and data inversion. Hence, the reverberation could be modeled with MOCASSIN, and the results have been included in Fig. (17). For simplicity, Lambert's law was used with values of the scattering coefficient $\mu$ that were constant for each direction. Reasonable fit, up to ranges of about $7 \mathrm{~km}$ beyond which the experimental data are dominated by noise, was obtained with $\mu=-14 \mathrm{~dB}$ for the Run 9 direction and $\mu=-18 \mathrm{~dB}$ for the Run 11 direction.

Discrepancies between the measured and modeled RL must be expected for several reasons. In particular, the bathymetric sections for the modelling are strictly twodimensional, whereas an A-scan represents a beam which includes energy originating from bottom areas outside the bathymetric cross-section. It is easy to envisage significant 3D effects, with interfering reverberation from adjacent horizontal directions where sea mounts appear differently. The NNE and Run 9 directions are reasonably close, but the bottom topography changes notably between them, Figs. (16, 17).

The modelling indicates a stronger backscattering from the Run 9 direction than from the Run 11 direction. The stronger backscattering implies a harder bottom [11, Sec. 8.13], and our previous evidence for a difference between the bottom types at Run 9 and Run 11 is supported.

\section{CONCLUSIONS}

Transmission loss and reverberation from the Baltic have been measured and analyzed. Focus has been given to two $30 \mathrm{~km}$ long runs with range-dependent summer sound speed profiles and varying bottom depths between 50 and $170 \mathrm{~m}$. LFM pulses centered between 500 and $5500 \mathrm{~Hz}$ were used.

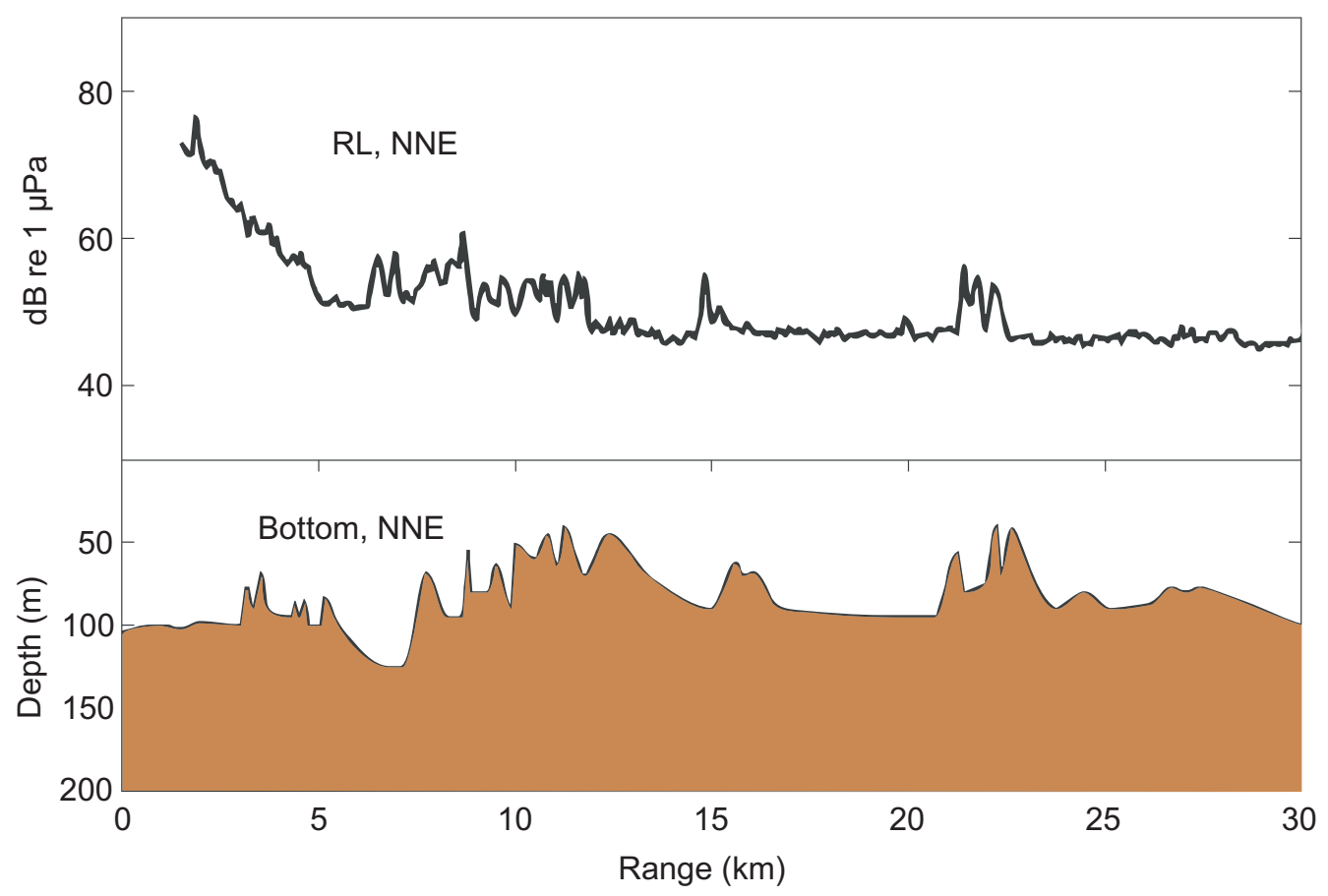

Fig. (16). Bottom profile in the NNE direction (oriented west 10 degrees from Run 9, see Fig. (2)) compared to corresponding measured RL from a 1.0-2.0 kHz LFM pulse. The peaks are usually outcrops, whereas the valleys are filled with sediments. Some of the sea mounts give very distinct echoes. 

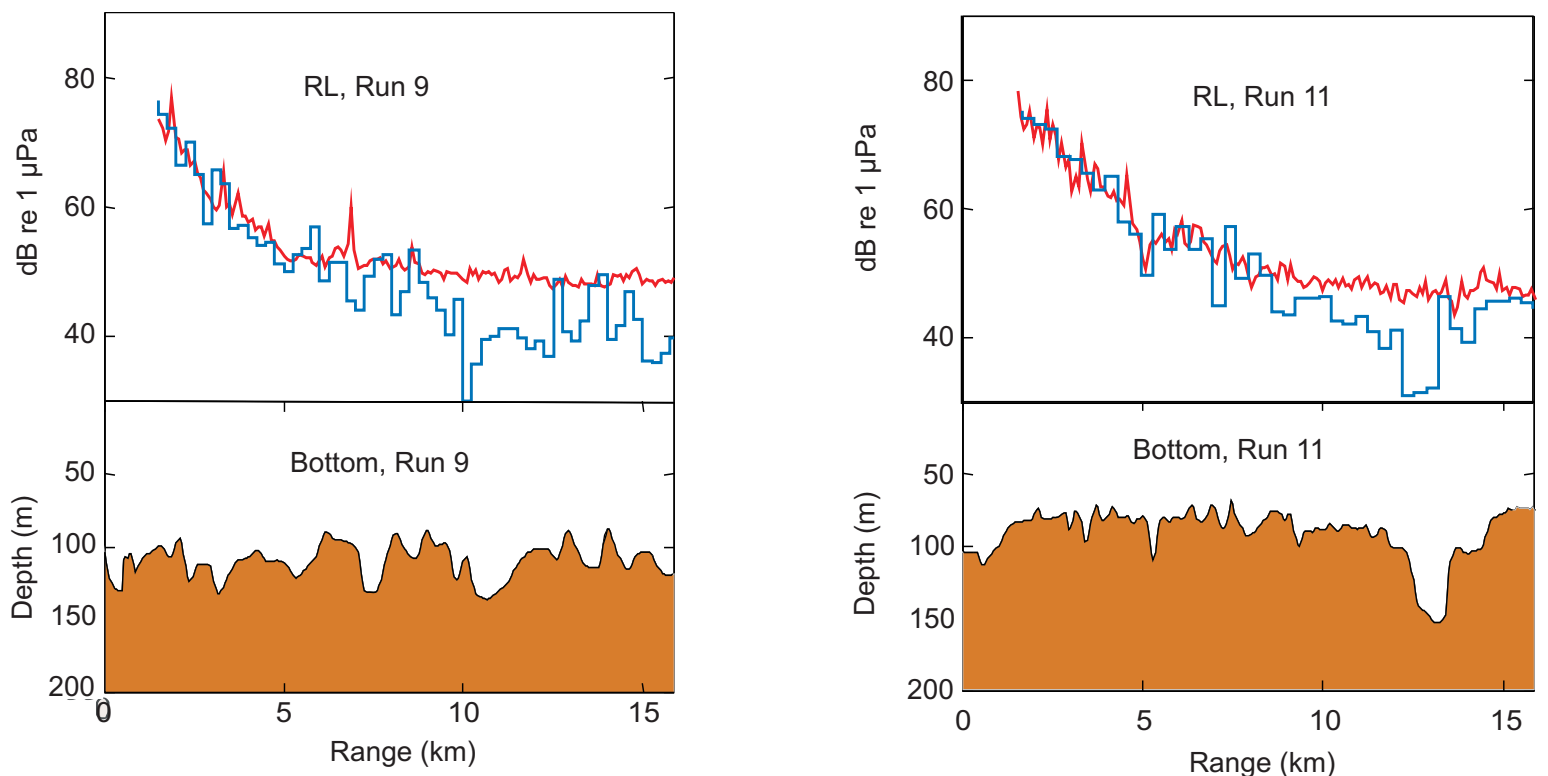

Fig. (17). Bottom profiles in the two TL directions (Run 9 and Run 11 indicated in Fig. (2)) compared to corresponding measured RL from a 1.0-2.0 kHz LFM pulse (grey curves in upper panel). Corresponding results computed by the MOCASSIN model, with bottom reflection loss parameters as determined by the genetic TL data inversion, are also shown (black curves in upper pane). Lambert's law was used for the computations, with $\mu=-14 \mathrm{~dB}$ for the Run 9 direction and $\mu=-18 \mathrm{~dB}$ for the Run 11 direction.

Low transmission loss was recorded in a sound channel at mid depth. Outside the sound channel, the loss was higher, especially for Run 11 .

The analysis, including inversion for range-dependent bottom parameters, indicates strong backscattering. Such results are consistent with previous experiments in the Stockholm archipelago. Large values of the Lambert's law scattering coefficient, $\mu=-14$ or $-18 \mathrm{~dB}$, are needed to explain the strong bottom reverberation. The channel effect observations, the inversion results, and the reverberation measurements provide consistent evidence that the bottom at Run 9 is less soft than the one at Run 11.

The experimentally determined frequency dependence was weak, with good transmission for all frequencies between 1 and $5 \mathrm{kHz}$. However, there are some indications of an optimum frequency of propagation at about $4 \mathrm{kHz}$ for the two runs. It should be noted that the unusually good propagation conditions rely on the USC.

An implication for long range active surveillance sonar is that in the Baltic, in areas similar to the experiment site, low frequency is not needed to achieve long detection distances. The possibility of using medium frequencies $(3-6 \mathrm{kHz})$ is advantageous, since this makes it possible to use sonar signals with large bandwidths, giving better suppression of the reverberation with matched filtering.

\section{ACKNOWLEDGMENTS}

We thank FWG for providing excellent experimental resources and for an inspiring cooperation, in particular Dr. Wolfgang Jans, Dr. Lothar Ginzkey and Dr. Hans-Georg Schneider. We also thank the crews of FWS Planet, MzB Schwedeneck and HMS Urd for their support during the experiment. Peter Karlsson, Ron Lennartsson, Bernt Nilsson,
Marie Olsson, Per Morén, Örjan Staaf, Gunnar Sundin, and Per Söderberg at FOI contributed to the analysis work.

\section{REFERENCES}

[1] Schneider HG. MOCASSIN sound propagation and sonar range prediction model for shallow water environments. Technical Report 1990-9, FWG: Kiel, Germany 1990.

[2] Vadov RA. Long-range sound propagation in the central region of the Baltic sea. Acoust Phys 2001; 47: 150-9. (Translation from Akust Zh 2001; 47: 189-199.)

[3] Gerdes F, Hofmann H-G, Nissen I. Comparison of measured and modelled acoustic propagation loss in the Baltic Sea: Proceedings $7^{\text {th }}$ European Conference Underwater Acoustics; Delft, the Netherlands 2004.

[4] Gerdes F, Hofmann, H-G, Jans W, Künzel S, Nissen I, Dol H. Measurements and simulations of acoustic propagation loss in the Baltic Sea: Proceedings $3^{\text {rd }}$ Conference on Underwater Acoustic Measurements; Nafplion, Greece 2009.

[5] Jensen FB, Kuperman WA. Optimum frequency of propagation in shallow water environments. J Acoust Soc Am 1983; 73: 813-9.

[6] Gelumbauskaité L-Z, Holmquist T, Litvin V, et al. Bathymetric map of the central Baltic Sea, scale 1:1500000. In: Gelumbauskaité L-Z, Ed. LGT Series of Marine Geological Maps/SGU Series Ba no. 54, Vilnius-Uppsala 1998.

[7] Francois RE, Garrison GR. Sound absorption based on ocean measurements. Part II: Boric acid contribution and equation for total absorption. J Acoust Soc Am 1982; 22: 1879-90.

[8] Jensen FB, Kuperman WA, Porter MB, Schmidt H. Computational ocean acoustics. AIP Press: New York 1994.

[9] Akal T, Jensen FB. Effects of the sea-bed on acoustic propagation. In: Pace NG, Ed. Symp. on physics of sound in sediments, Bath, U.K. 1983, pp. 225-32.

[10] Eller AI, Gershfeld DA. Low-frequency acoustic response of shallow water ducts. J Acoust Soc Am 1985; 78: 622-31.

[11] Urick RJ. Principles of Underwater Sound. McGraw-Hill: New York 1983.

[12] McDonough RN, Whalen AD. Detection of Signals in Noise. $2^{\text {nd }}$ ed. San Diego, CA: Academic Press 1995.

[13] Matlab Signal Processing Toolbox version 6.5 manual.

[14] Nielsen RO. Sonar Signal Processing. Nortwood, NA: Artech House 1991.

[15] Burdic WS. Underwater Acoustic System Analysis. Los Altos: Prentice-Hall 1991. 
[16] Karasalo I, Sundstrom A. JEPE - a high-order PE-model for rangedependent fluid media. In: Proceedings of the 3rd European Conference Underwater Acoustics, Heraklion, Crete, Greece 1996, pp. 189-94.

[17] Larsson E, Abrahamsson L. Helmholtz and parabolic equation solutions to a benchmark problem in ocean acoustics. J Acoust Soc Am 2003; 113: 2446-54.

[18] Ivansson S, Morén P, Parastates E, Westerlin V. Hydroacoustical experiments for determination of sediment parameters. In: Proc. Oceans 94 Part III, Brest, France 1994, pp. 207-12.

[19] Sambridge M, Drijkoningen G. Genetic algorithms in seismic waveform inversion. Geophys J Int 1992; 109: 323-42.

[20] Whitley D, Starkweather T. Genitor II: A distributed genetic algorithm. J Exp Theor Artif Intell 1990; 2: 189-214.

[21] Swann WH. Direct search methods, in Murray W, Ed. Numerical Methods for Unconstrained Optimization. Academic Press: London and New York 1972, pp. 13-28.
[22] McDaniel ST. Mode conversion in shallow-water sound propagation. J Acoust Soc Am 1977; 62: 320-5.

[23] McDaniel ST, McCammon DF. Mode coupling and the environmental sensitivity of shallow-water propagation loss predictions. J Acoust Soc Am 1987; 82: 217-23.

[24] Akal T. Acoustic characterization of the sea floor: experimental techniques and some examples from the Mediterranean Sea. In: Hampton L, Ed. Physics of Sound in Marine Sediments, La Spezia, Italy 1974, pp. 447-80.

[25] Wegge J. Correlation between sonar echoes and sea bottom topography, In: Pace NG, Jensen FB, Eds. Impact of Littoral Environmental Variability on Acoustic Predictions and Sonar Performance, Kluwer Academic Publishers, The Netherlands 2002, pp. 319-26.

[26] Preston JR. Reverberation at the Mid-Atlantic Ridge during the 1993 ARSRP experiment seen by R/V Alliance from 200-1400 Hz and some model inferences. J Acoust Soc Am 1999; 107: 237-59.

Received: December 24, 2009

Revised: June 10, 2010

Accepted: October 26, 2010

(C) Pihl et al.; Licensee Bentham Open.

This is an open access article licensed under the terms of the Creative Commons Attribution Non-Commercial License (http://creativecommons.org/licenses/by$\mathrm{nc} / 3.0 /$ ) which permits unrestricted, non-commercial use, distribution and reproduction in any medium, provided the work is properly cited. 